\title{
Tropospheric CO observed with the NAST-I retrieval methodology, analyses, and first results
}

\author{
Daniel K. Zhou, William L. Smith, Xu Liu, Jun Li, Allen M. Larar, \\ and Stephen A. Mango
}

\begin{abstract}
High-resolution infrared spectra from aircraft and space-based observations contain information about tropospheric carbon monoxide $(\mathrm{CO})$ as well as other trace species. A methodology for retrieving tropospheric CO from such remotely sensed spectral data has been developed for the National Polar-Orbiting Operational Environmental Satellite System's Airborne Sounder Testbed-Interferometer (NAST-I). CO profiles of the troposphere, together with its thermodynamic properties, are determined by use of a three-stage retrieval approach that combines the algorithms of physically based statistical eigenvector regression, simultaneous and iterative matrix inversion, and single-variable error-minimization CO profile matrix inverse retrieval. The NAST-I is collecting data while it is aboard high-altitude aircraft throughout many field campaigns. Detailed retrieval analyses based on the NAST-I instrument system along with retrieval results from several recent field campaigns are presented to demonstrate NAST-I CO retrieval capability. (c) 2005 Optical Society of America
\end{abstract}

OCIS codes: $\quad 010.0010,010.1280,280.0280$.

\section{Introduction}

Tropospheric chemical reactions involving carbon monoxide $(\mathrm{CO})$ extend their influence to the global climate through accumulation of greenhouse gases. Trace amounts of $\mathrm{CO}$ are found in the atmosphere. The significance of $\mathrm{CO}$ in atmospheric chemistry was recognized when a photochemically driven chain reaction was proposed to link the tropospheric cycles of $\mathrm{CO}$, methane $\left(\mathrm{CH}_{4}\right)$, and ozone $\left(\mathrm{O}_{3}\right)$ with those of the hydroxyl radical $(\mathrm{OH})$ and the hydroperoxyl radical $\left(\mathrm{HO}_{2}\right) .{ }^{1} \mathrm{CO}$, because of its relatively long lifetime, can be transported a great distance from its original source. Air particles downwind of combustion (e.g., biomass, fossil fuels) often show elevated $\mathrm{CO}$ and $\mathrm{O}_{3}$ as a result of photochemical production. ${ }^{2}$ The impor-

D. K. Zhou (daniel.k.zhou@nasa.gov), X. Liu, and A. M. Larar are with the Science Directorate, NASA Langley Research Center, 21 Langley Boulevard, Hampton, Virginia 23681. W. L. Smith is with the Center for Atmospheric Sciences, Hampton University, Hampton, Virginia 23668. J. Li is with the Space Science and Engineering Center, University of Wisconsin-Madison, 1225 West Dayton Street, Madison, Wisconsin 53706. S. A. Mango is with the National Polar-Orbiting Operational Environmental Satellite System Integrated Program Office, Suite 1450, 8455 Colesville Road, Silver Spring, Maryland 20910.

Received 7 June 2004; accepted 11 November 2004.

$0003-6935 / 05 / 153032-13 \$ 15.00 / 0$

(C) 2005 Optical Society of America tance of improving our knowledge of tropospheric chemical gases relating to environmental health and the magnitude of global climate change has been recognized. ${ }^{3}$ The critical role of satellite and aircraft observations has been established as the necessary global and regional observations have been provided for understanding the complex chemistry and transport processes involved in regional air pollution chemistry and its influence on the global environment.

In December 1999, the Measurement of Pollution in the Troposphere (MOPITT) instrument was launched aboard the Terra satellite ${ }^{4-6}$ for spacebased measurement of $\mathrm{CO}$ and $\mathrm{CH}_{4}$. The Tropospheric Emission Spectrometer (TES) has been launched aboard the Aura satellite and is detecting tropospheric trace species. One of the objectives of these missions is to monitor the global $\mathrm{CO}$ distribution. ${ }^{7}$

The observations from hyperspectral infrared Fourier-transform spectrometers flown on aircraft and spacecraft have been used to infer the atmospheric temperature, moisture, and concentration of trace gas species by use of radiative transfer equation inversion techniques. ${ }^{8-11}$ The National Polar-Orbiting Operational Environmental Satellite System (NPOESS) Airborne Sounder TestbedInterferometer (NAST-I) has been successfully operating on high-altitude aircraft (i.e., ER-2 and 
Proteus) since 1998.12-15 The NAST-I provides high spatial linear resolution, equal to $13 \%$ of the aircraft's altitude at nadir, scanning, and high spectral resolution $\left(0.25-\mathrm{cm}^{-1}\right)$ measurements within the spectral region $645-2700 \mathrm{~cm}^{-1}$ from the NASA ER-2 or the Northrop Grumman Proteus aircraft flown at an altitude $15-20 \mathrm{~km}$. The NAST-I is designed to support the development of future satellite temperature and moisture sounders such as the Infrared Atmospheric Sounding Interferometer (IASI) on the METOP satellite (to be launched in 2006), the CrossTrack Infrared Sounder (CrIS) on the NPOESS Preparatory Project (NPP) (in 2006) and NPOESS (in 2008-2010) satellites, and the Geostationary Imaging Fourier Transform Spectrometer (GIFTS) and the Hyperspectral Environmental Suite (HES) to fly on geostationary satellites (in approximately 2013). It has provided hyperspectral resolution remote-sensing data for simultaneously retrieving atmospheric temperature, water vapor, $\mathrm{O}_{3}$ and $\mathrm{CO}$, along with cloud and surface properties. The temperature and moisture retrievals under clear-sky conditions have been validated. ${ }^{15}$ The object of the measurement of chemical abundance (such as tropospheric $\mathrm{O}_{3}$ and $\mathrm{CO}$ ) is the monitoring of air quality and the initialization of climate process models. Several existing inversion algorithms for retrieving $\mathrm{CO}$ from nadir remote-sensing measurements in the infrared have been summarized. ${ }^{16}$ The general physical retrieval approach presented here is to use the socalled the regularization algorithm (or minimuminformation method) in a nonlinear least-squares spectral radiance fitting mode. The primary objectives of the current study are the further development of the NAST-I retrieval algorithm for the simultaneous retrieval of thermodynamic parameters and chemical species, such as $\mathrm{CO}$ and $\mathrm{O}_{3}$. Results of retrieval analyses based on simulated data, retrieval sensitivity calculations, and aircraft dataretrieval error assessments are presented here. Examples of $\mathrm{CO}$ abundances, retrieved with the algorithm described herein applied to recent NAST-I field campaign data, are validated with in situ tracegas measurements made from other aircraft.

\section{Description of the Forward and Inverse Radiative Transfer Models}

\section{A. Fast-Forward Model and Weighting Functions}

The Optimal Spectral Sampling (OSS) fast radiative transfer model, 17 which was developed for NAST-I analyses and used in NAST-I retrieval algorithms, is briefly described here. In the OSS approach, which is an extension of the exponential sum fitting transmittance method, ${ }^{18}$ radiance for each instrument channel is represented as a linear combination of radiances computed at a few preselected monochromatic frequencies within the domain spanned by the instrument's line shape function. ${ }^{19}$ On average, only 2.6 monochromatic radiance calculations are needed for each NAST-I channel. These radiances are calculated by use of an optical depth lookup table, which is generated for various atmospheric gases at different temperatures and pressures. As with other fast radiative transfer models, the model parameters (i.e., weights and locations for monochromatic frequencies) are obtained off line by training under various atmospheric and surface conditions and various observation geometries. One performs the optimal selection of monochromatic frequencies and the computation of the weights by minimizing the difference between radiances derived from the approximate OSS formulation and those obtained with a reference line-by-line model. The NAST-I OSS model is designed to rapidly compute transmittances and radiances for several major atmospheric species (i.e., $\mathrm{CO}_{2}, \mathrm{H}_{2} \mathrm{O}, \mathrm{O}_{3}$, and $\mathrm{CO}$ ) from any aircraft-sensor altitude, a capability that greatly assists airborne instruments such as the NAST-I to achieve accurate forward model simulation. We examine the accuracy of this fast-forward model by comparing the spectral radiance (or brightness temperature) of the OSS model with that of the Line-by-Line Radiative Transfer Model $^{20}$ (LBLRTM, version 8) over a set of 106 atmospheric profiles randomly selected from the $\mathrm{Na}-$ tional Oceanic and Atmospheric Administration's 1988 radiosonde database (NOAA88, a total of 7547 profiles). The mean standard deviation error (STDE) over 4424 regression inversion channels, 687 simultaneous matrix inversion channels, and $160 \mathrm{CO}$ profile enhancement inversion channels is $0.068,0.073$, and $0.105 \mathrm{~K}$, respectively. A detailed OSS model description can be found elsewhere, ${ }^{19}$ and assessments of its performance and accuracy are in preparation for publication. ${ }^{21}$

The weighting function, or Jacobian matrix (defined as the derivative of radiance with respect to an atmospheric parameter), is commonly used to illustrate the spectral channel retrieval sensitivity to its radiance. In the research reported here, weighting functions are calculated by an analytical scheme or a numerical perturbation method. ${ }^{22,23}$ The Jacobian matrices produced by the NAST-I OSS fast radiative transfer model shown in Fig. 1 are for gases of constant mixing ratios (e.g., $\mathrm{CO}_{2}$ and $\mathrm{N}_{2} \mathrm{O}$ ), for $\mathrm{H}_{2} \mathrm{O}$, and for $\mathrm{CO}$ simulated as would be observed from an altitude of $51 \mathrm{mb}$ [mbars $(1 \mathrm{mbar}=100 \mathrm{~Pa})]$ by use of the U.S. standard atmosphere with a surface skin temperature of $290.5 \mathrm{~K}$. Note that the weighting functions associated with constant mixing ratio gases and water vapor have peaks distributed throughout the range of pressure altitude, indicating that the channels in these spectral regions can be used for temperature and water-vapor profile retrieval. ${ }^{15}$ The $\mathrm{CO}$ weighting functions also show the vertical sensitivity in the troposphere, which is discussed in Section 3 below with respect to CO-retrieval sensitivity for NAST-I spectral resolution and instrument noise.

\section{B. Training Data, Linear Statistical Regression, and Simultaneous Matrix Inversion}

Inasmuch as the retrieval problem described is ill posed, additional information is needed to constrain the solution. The radiosonde temperature and mois- 

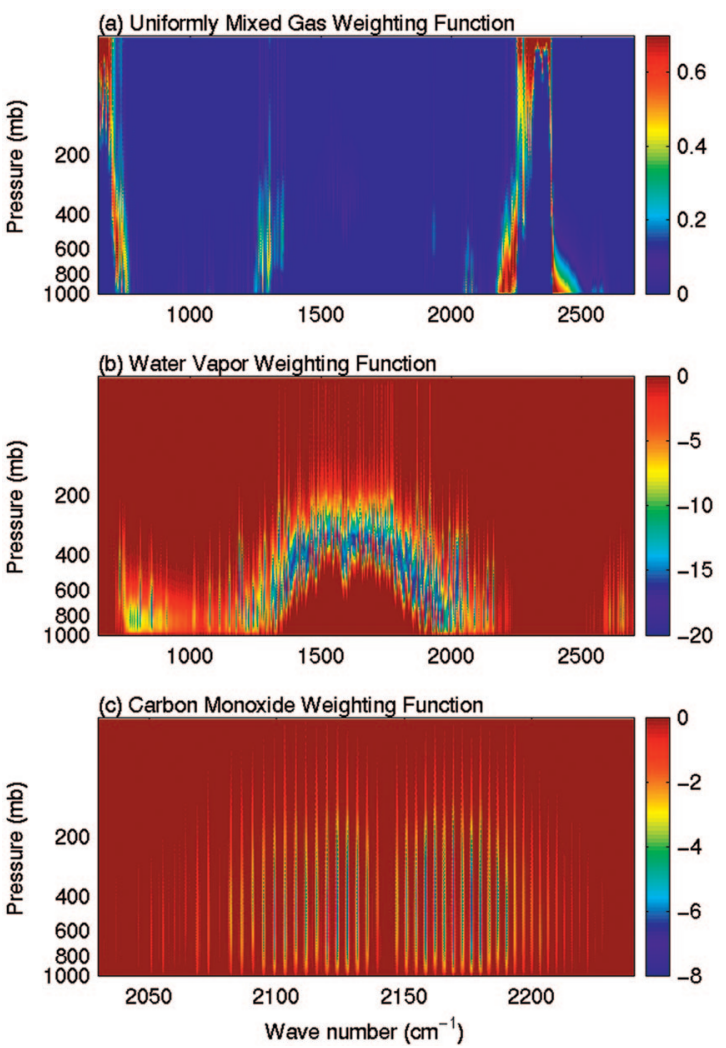

Fig. 1. Weighting function matrices of (a) fixed gas (constant mixing ratio), (b) water vapor, and (c) CO of NAST-I channels calculated with the U.S. standard atmosphere. The peak (or valley) of the weighting function of fixed gas (water vapor, CO) of each channel is indicated by a wave number associated with a pressure altitude.

ture profiles obtained in the same season (approximately 3 months) of previous years and over a geophysical location within a radius of approximately $900 \mathrm{~km}$ are used for the training data set (usually a few thousand profiles are used). ${ }^{15}$ Here, statistical samples of $\mathrm{CO}$ profiles are used with radiosonde temperature and water-vapor profiles to produce coefficients for regression retrieval. The $\mathrm{CO}$ training profile statistics are important for estimating the $\mathrm{CO}$ profile in the altitude range where $\mathrm{CO}$ Jacobian matrices indicate weak radiance sensitivity. Unfortunately, CO profiles are not sampled simultaneously with the radiosonde temperature and moisture profiles used for the statistical regression retrieval. As a result, CO abundance profiles must be assembled for each radiosonde profile from the relationship between thermodynamic parameters (i.e., temperature and moisture) and CO abundance profiles on measurements from aircraft made during several atmospheric chemistry field campaigns. The same methodology is used to manufacture $\mathrm{O}_{3}$ profiles for statistical retrieval algorithm training.

The regression retrieval is used as the initial, or first-guess, profile as a constraint for a matrix inverse retrieval of the thermodynamic and trace-gas variable profiles. The description of a linear statistical regression retrieval method used here, called empir- ical orthogonal function (EOF) retrieval, can be found elsewhere. ${ }^{9}$ Detailed validations conducted by use of results from numerous NAST-I field campaigns have indicated that thermodynamic parameters (i.e., temperature and water-vapor profiles) can be accurately retrieved with this physically based EOF regression method. ${ }^{15}$

Once the first guess is generated from the regression technique described above, a nonlinear iterative procedure is set up to produce a retrieval that is an improvement of the first guess. The TwomeyTikhonov solution (i.e., the regularization algorithm or the minimum-information method) ${ }^{24-27}$ is chosen for a NAST-I physical retrieval methodology that does not use forecast analysis. The NAST-I regression result serves as the first guess in the physical retrieval processing. Detailed NAST-I physically based EOF regression and simultaneous matrix inversion (i.e., nonlinear multivariable physical iteration) can be found elsewhere ${ }^{15}$; they are described herein as inversion stage 1 (denoted REG hereafter) and inversion stage 2 (denoted SMI hereafter), respectively. The same methodologies have been expanded to include retrieval of trace species (i.e., $\mathrm{CO}$ and $\mathrm{O}_{3}$ ).

\section{CO Profile Enhancement}

SMI provides an improvement in the accuracy of the thermodynamic parameter retrievals and enhances the vertical profile characteristics of the $\mathrm{CO}$ retrievals. However, the absolute accuracy of $\mathrm{CO}$ profile retrieval can be further improved. The spectral channels used for this nonlinear SMI are carefully selected. The optimal channels where the spectroscopy is well known should provide minimal redundant information for both temperature and atmospheric constituents; in addition, they are the channels that have the smallest detector noise, calibration error, and forward model uncertainty. These channels are chosen to lie between absorption line centers because these spectral locations are where the sharpest weighting functions occur. These $\mathrm{CO}$ weighting functions are shown in Fig. 2(a) for the channels selected for CO to be simultaneously retrieved with other parameters. These CO channels satisfy the condition of "providing least-redundant information"15 as desired for SMI methodology. However, there are many other CO channels that can also provide information for CO-retrieval enhancement when $\mathrm{CO}$ is dealt with only as a stand-alone retrieval; therefore these channels do not need to satisfy the condition of providing least-redundant information as desired in the simultaneous inversion process. The $\mathrm{CO}$ weighting functions of all NAST-I CO-sensitive channels are shown in Fig. 2(b). Retrieval channels are limited to the CO (1-0) vibration-rotation band region (approximately $2050-2250 \mathrm{~cm}^{-1}$ ). These channels provide information on the $\mathrm{CO}$ profile; even though many channels are redundant in spectral information, they are independent in terms of random measurement noise. Thus as many channels as possible should be 

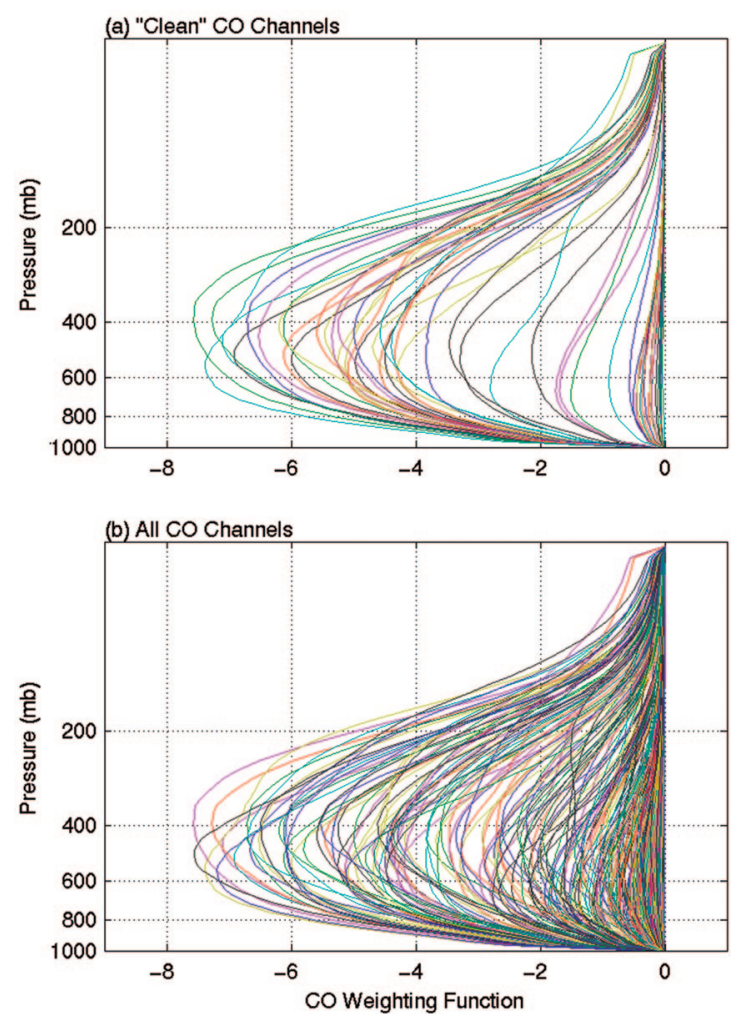

Fig. 2. $\mathrm{CO}$ weighting functions: (a) $\mathrm{CO}$ channels barely influenced by any other gases used in the SMI and (b) all channels sensitive to $\mathrm{CO}$ that can be used in CO PEI.

used for subsequent minimization of CO-retrieval error. In this final $\mathrm{CO}$ physical retrieval, only $\mathrm{CO}$ mixing ratios are the variables in the iterative inversion process. The nonlinear matrix inversion (or minimum-information method) described above is then repeated to retrieve $\mathrm{CO}$ profiles exclusively by use of almost all CO-sensitive channels within its (1-0) band region. Several checks are made again for retrieval quality control. The rms of quantity (i.e., between observed and calculated radiances) from all selected CO channels is computed to check the convergence or divergence, which then decides whether the iteration is to be continued or stopped. The degree of convergence of each iteration depends on the accuracy of the previous atmospheric and surface state. This final CO profile enhancement inversion (PEI) is the single-variable matrix inversion (inversion stage 3). The NAST-I retrieval package has a friendly setup to allow the user to choose the retrieval processing stages, which depend on the parameters to be retrieved, retrieval accuracy, and computational time requirements.

\section{CO Retrieval Simulation and Analyses}

Analyses with the physically based REG and the nonlinear SMI for the NAST-I instrument have been performed. These retrieval methodologies were expanded to include CO retrieval. Detailed $\mathrm{CO}$-retrieval simulation and analyses using the $\mathrm{CO}$ inversion scheme described above were performed to demonstrate the CO-retrieval sensitivity and accuracy of the NAST-I. The CO weighting functions indicate the radiance sensitivity to amount of $\mathrm{CO}$ (i.e., $\mathrm{d} R / R=\mathrm{COWFdCO} / \mathrm{CO}$, where $R$ is radiance, $\mathrm{COWF}$ is the $\mathrm{CO}$ weighting function and $\mathrm{CO}$ is the $\mathrm{CO}$ mixing ratio). Simulation analyses presented in this section include an assessment of NAST-I CO vertical information content performed with the averaging kernels and statistical analyses based on retrieval simulations with a set of 300 atmospheric profiles (with radiosonde temperature and moisture profiles and manufactured $\mathrm{CO}$ and $\mathrm{O}_{3}$ profiles). The error contributions to the $\mathrm{CO}$ retrieval are simulated for the NAST-I instrument. Two sets of analyses are shown to demonstrate how the retrieval accuracy is affected by first-guess accuracy. In addition, independent retrieval analyses were performed over a set of in situ measured CO profiles (a total of 69 profiles containing the data up to $300 \mathrm{mb}$ ) to show retrieval accuracy. Statistical analysis of the vertical information content over this data set is performed through application of principal component analysis.

\section{A. Vertical Resolution Assessment}

The averaging kernels are the character functions of the retrieval and represent the way in which a true atmospheric state is transformed into a derived atmospheric state by the retrieval system. Detailed formulation and definition of the averaging kernel can be found elsewhere. ${ }^{5,28}$ The averaging kernels define the vertical resolution of the retrieved atmospheric state. The averaging kernels specify the relative contribution of each element of the true state vector to the estimated state vector at a particular layer, and the vertical resolution for the retrieval can be characterized by the full width at half-height. ${ }^{29}$ Averaging kernel $A$ describes the dependence of retrieved state vector $\hat{x}$ on true state vector $x$ through the relation $A=(\partial \hat{x} / \partial x) .{ }^{6}$ This relation is used in this study. An averaging kernel can be computed with NAST-I instrument characteristics by use of forward and inversion simulations based on CO profile perturbation at a corresponding atmospheric layer. Figure 3 shows averaging kernels simulated for the NAST-I instrument by use of the U.S. standard atmosphere (with a surface/atmosphere thermal contrast of $3.0 \mathrm{~K}$ ). Selected significant layers have been plotted for clarity; they show the most sensitive altitude region as being approximately $800-300 \mathrm{mb}$.

\section{B. Sources of Retrieval Error}

It is essential to estimate the $\mathrm{CO}$ retrieval error and the sources of error. However, under the circumstances of this type of ill-posed multiparameter simultaneous retrieval, the retrieval error spreads throughout all retrieved parameters; therefore performing an absolute CO-retrieval-error analysis is complicated. In the research reported here, the relative CO-retrieval-error estimation is performed with a few assumptions. The vertical weighting uncertainty through the CO-retrieval processing is ignored. The CO-retrieval-error analysis is simulated 


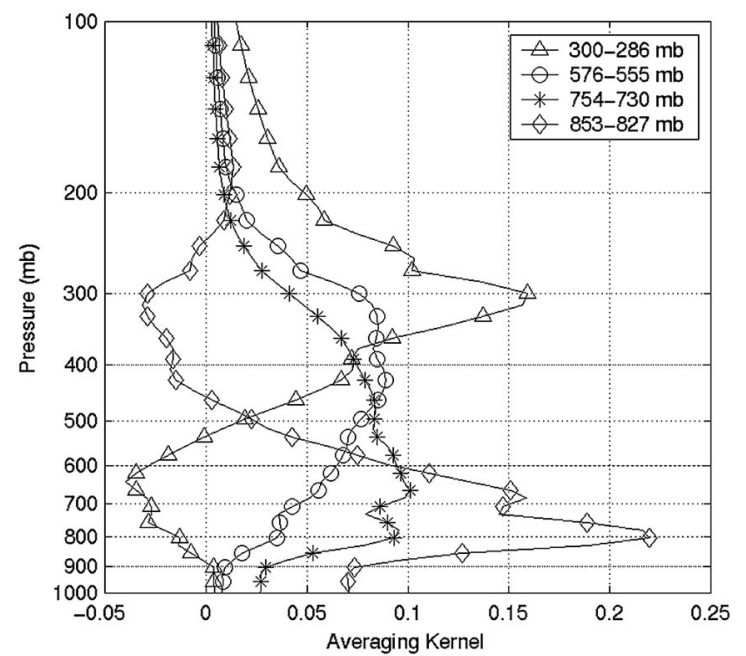

Fig. 3. Selected significant averaging kernels calculated for retrieving the U.S. standard atmosphere with NAST-I instrument specifications. Perturbed layers are indicated.

with 300 subindependent samples (with nominal CO, i.e., comparable to that used for regression coefficients); the instrument noise is added to simulated NAST-I radiance for retrieval processing. CO PEI is performed with the true parameters used as first guesses, except that one of the parameters is perturbed. One then compares the retrieved CO profiles with the truth to compute the mean difference and the STDE contributed by that perturbed parameter. The simulation can also be performed without any perturbed parameters to produce a CO STDE that is contributed by the instrument noise on CO-retrieval channels. The instrument noise and forward model error are key sources of the retrieval error, introducing retrieval errors in thermodynamic parameters. One can add the OSS model error addressed in Subsection 2.A to simulated NAST-I radiance to estimate CO-retrieval error. Note that the LBLRTM error (including the HITRAN database error such as CO line strength uncertainty) is excluded here. Here we assume that the surface skin temperature, surface emissivity, and solar radiation are combined to yield the effective surface skin temperature, which has an error of $1.5 \mathrm{~K}$; we also assume a $1.0-\mathrm{K}$ error for the temperature profile and a $20 \%$ error for water vapor through all altitudes. These estimations are based on retrieval analyses and validations over a large diversity of cases. NAST-I instrument noise is included in all analyses performed here. The CO-retrieval errors (i.e., deviations from the truth) introduced by the perturbations of those parameters, as well as the fast-forward model error, are estimated. The mean CO profile difference and the STDE from the perturbed parameters, and the fast-forward model error, are shown in Figs. 4(a) and 4(b), respectively. These are the major parameters that make significant contributions to the radiances in the CO $4.7-\mu \mathrm{m}$-band region. The retrieval errors of these parameters propagate during $\mathrm{CO}$ retrieval and contribute significantly to the CO-retrieval error. In addition, the

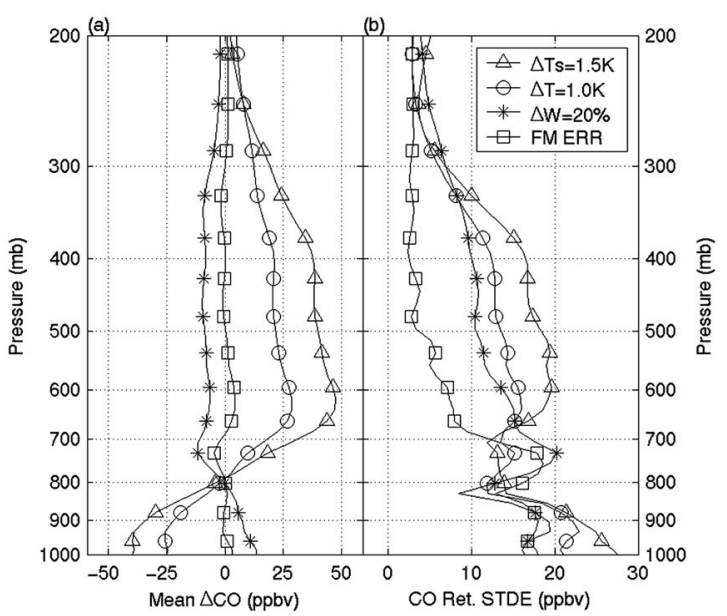

Fig. 4. CO-retrieval error introduced by the other retrieval parameter uncertainties: the skin temperature $(1.5 \mathrm{~K})$, the temperature profile ( $1 \mathrm{~K}$, circles), the water-vapor profile ( $20 \%$, asterisks), the fast-forward model error (FM ERR).

retrieval error is dependent on the accuracy of the first guess because the retrieval is ill posed; further discussions appear in the following subsections.

\section{Analyses with $50 \%$ Enlarged CO}

To test and magnify the retrieval ability, CO profiles are deliberately increased by a factor of 1.5 before NAST-I spectral radiances are simulated; these radiances are then added with NAST-I instrument noise $^{15}$ for retrieval analyses. The regression coefficients used here are still from the training set with nominal CO profiles. These simulations will show improvements rather than optimal retrievals through the retrieval stages. The atmospheric state (including $\mathrm{CO}$ ) is retrieved through all retrieval stages and used to simulate NAST-I radiances that are then compared with the original radiances to illustrate the accuracy of the retrieval obtained from the different stages. Figure 5(a) shows the spectral radiance STDE over this set of subindependent samples between the original radiance and the retrievalsimulated radiance; the CO 1-0 vibration-rotation band region is expanded in Fig. 5(b). The three curves are for REG, SMI, and CO PEI, respectively. Although accurate thermodynamic retrievals can be achieved rapidly through regression processing, chemical gases such as $\mathrm{CO}$ in the $4.7-\mu \mathrm{m}$ region do not have adequate regression-retrieval sensitivity for achieving good retrievals. The radiance STDE that results from SMI shows an overall improvement in both thermodynamic and chemically gaseous parameters. A significant convergence in the $\mathrm{CO}$ band region has been shown. The $\mathrm{CO}$ retrieval can then be further improved through a CO PEI, which is iterated to account for the nonlinear relationship between radiance and the $\mathrm{CO}$ mixing ratio. Although radiance convergence is improved in the SMI, the radiance convergence in the final CO PEI is small but still significant in minimizing CO retrieval error. The radiance STDE indicates the close radiance fitting in 

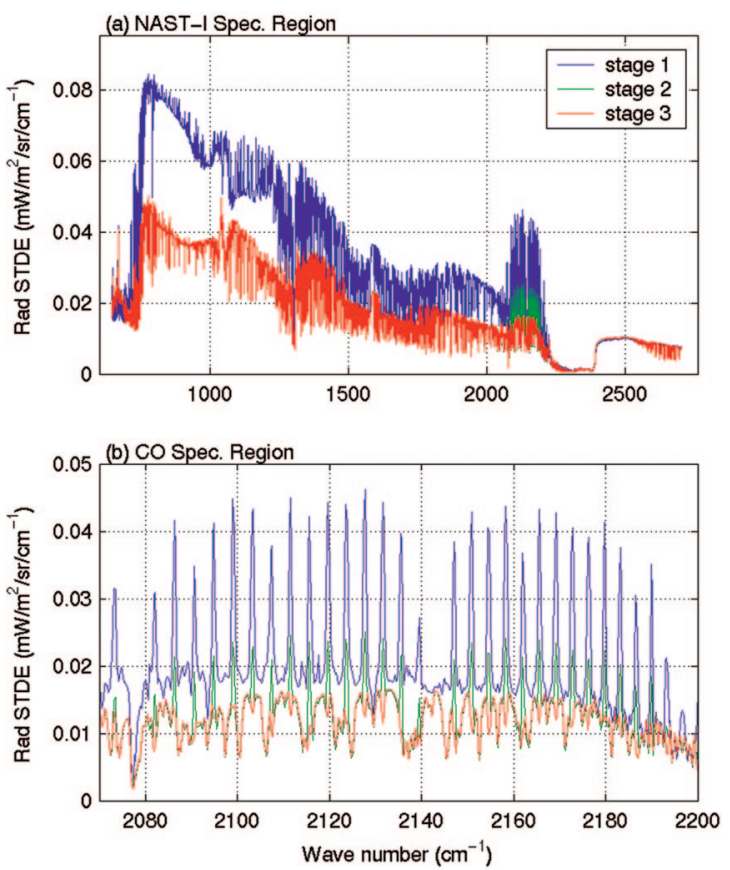

Fig. 5. Radiance STDE between original and retrieval-simulated radiances from three retrieval stages (bottom, the $\mathrm{CO}$ band region of the top; see text). Spec., spectral.

the CO 4.7- $\mu \mathrm{m}$-band region through CO PEI iterations.

The total CO column density is calculated by use of retrieved $\mathrm{CO}$ and temperature profiles to compare with its original truth. The accuracy of this parameter is dependent not only on the CO profile's accuracy but also on the temperature profile's accuracy. Despite the uncertainty in temperature retrieval, the total CO column densities from three retrieval stages are plotted against the truth in Fig. 6. It is noteworthy to point out again that the amount of $\mathrm{CO}$ to be

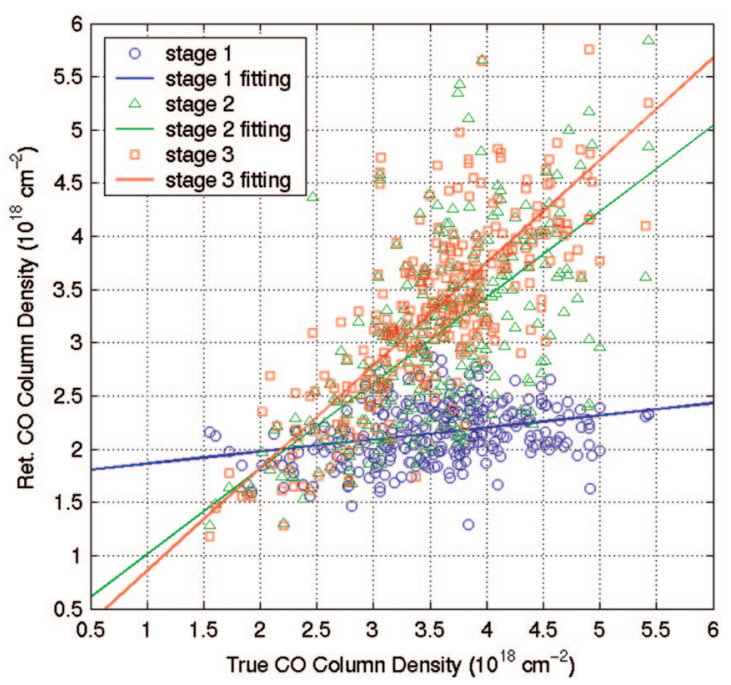

Fig. 6. Retrieved (Ret.) CO column densities versus truth for more than 300 subindependent samples and their linear fittings from each retrieval stage (see text for mean and standard deviation).

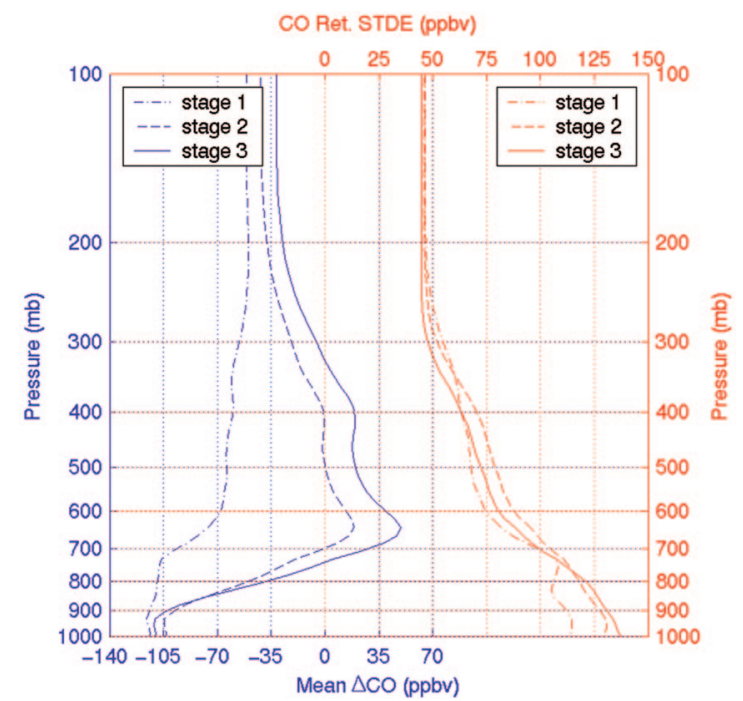

Fig. 7. Mean deviation (blue curves) and the STDE (red curves) of retrieved (Ret.) CO profiles from their truth in more than 300 samples. Three curves are the results from three retrieval stages (see text). ppbv, Parts in $10^{9}$ by volume.

retrieved is much larger than what is used in the statistical regression training data. As expected, the regression approach then gives poor $\mathrm{CO}$ retrieval results; however, the scattering-fitting line still shows an attempt to fit the truth. It implies that the statistical regression has somewhat positive retrieval sensitivity for CO. The statistical results of the absolute mean differences of this data set from three retrieval stages (with the STDE in parentheses) are 1.419 (0.699), $0.490(0.713)$, and $0.236(0.546)$, respectively, $\times 10^{18} \mathrm{~cm}^{-2}$. Both the average deviation and the STDE of CO column density are greatly minimized through the retrieval stages.

The mean differences between the retrieved $\mathrm{CO}$ profiles and their original truth, and their associated STDEs for three retrieval stages, are plotted in Fig. 7. The REG retrieval shows little convergence because the $\mathrm{CO}$ profiles to be retrieved are approximately $50 \%$ higher than the average $\mathrm{CO}$ profile used in the regression training data set. The physical retrievals tend to conserve the total $\mathrm{CO}$ amount, with the $\mathrm{CO}$ profile compensated for between atmospheric layers according to the $\mathrm{CO}$ weighting functions (shown in Fig. 2) that show the most sensitive altitude region located between approximately 300 and $800 \mathrm{mb}$. The $\mathrm{CO}$ retrieval in this vertical region is more sensitive, which results in more $\mathrm{CO}$ abundance being added to this region to compensate for regions below and above where CO has much less sensitivity. As one can see from Fig. 7, the first-guess CO profile obtained through the REG is doubtful because of its weak regression sensitivity. The physical retrieval relies on this unconvincing first guess, which introduces a large retrieval error. The STDE shown in Fig. 7 indicates a significant retrieval uncertainty in the profile. 

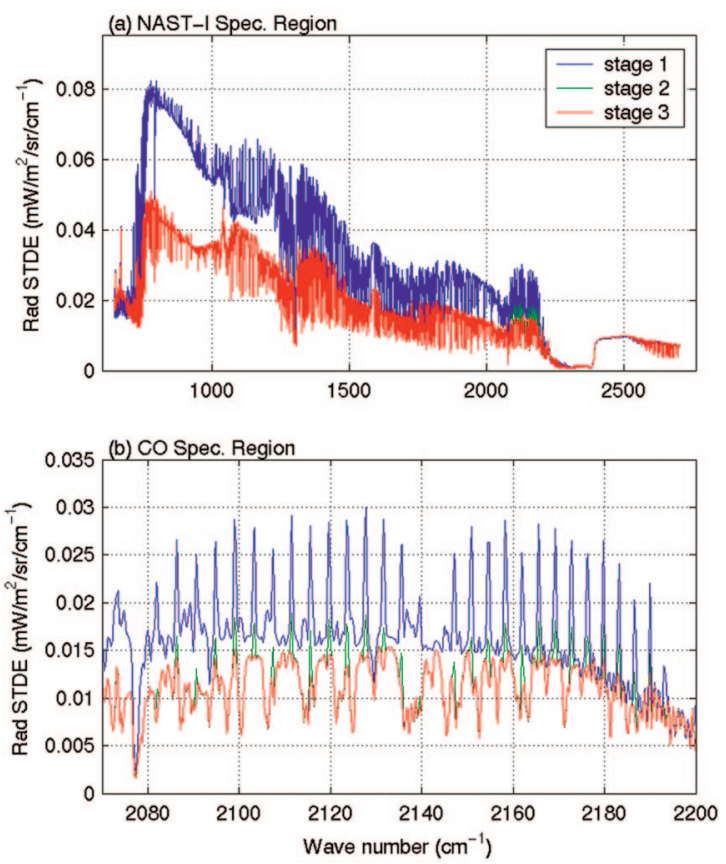

Fig. 8. Similar to Fig. 5 but for nominal CO retrieval (see text).

\section{Analyses with Nominal $\mathrm{CO}$}

The CO profile retrieval accuracy is dependent on the first guess. The above analyses are repeated with nominal CO measurements. Figure 8(a) shows the radiance STDE that results from physical SMI and the overall improvement in both thermodynamic and chemically gaseous parameters. A significant convergence in the $\mathrm{CO}$ band region has been shown [Fig. 8(b)]; CO retrieval can then be further improved through a final CO PEI. Figure 9 shows the retrieved CO column density compared with the truth. The statistical results of the absolute mean differences of this data set (with the STDE in parentheses) from three retrieval stages are $0.279(0.484), 0.063(0.393)$, and $0.085(0.362)$, respectively, $\times 10^{18} \mathrm{~cm}^{-2}$. The in-

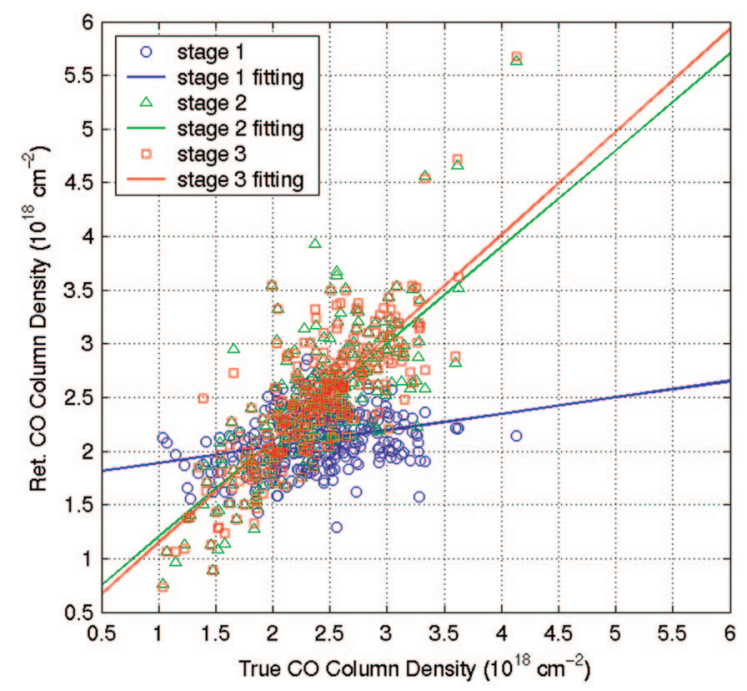

Fig. 9. Similar to Fig. 6 but for nominal CO retrieval (see text).

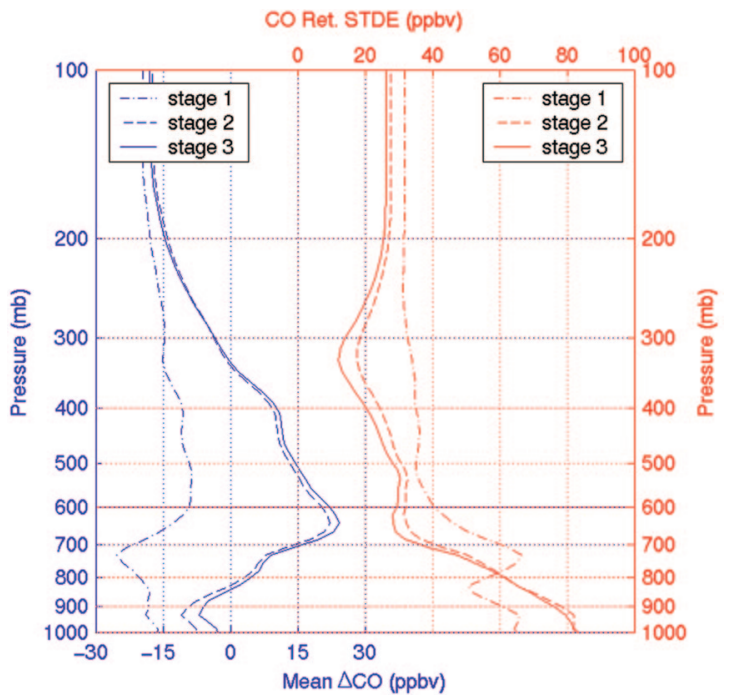

Fig. 10. Similar to Fig. 7 but for nominal CO retrieval (see text).

significant difference between the results of SMI and the final CO PEI is due to retrieval limitation and uncertainty. The mean differences between the retrieved CO profiles and their original truth, and their associated STDE for three retrieval stages, are plotted in Fig. 10. Figures 8-10 are similar to Figs. 5-7 but show a great improvement in the $\mathrm{CO}$ retrieval accuracy when the CO first guess is improved; in other words, the retrieval error depends on the accuracy of the first guess. Figure 10 gives a more realistic retrieval error than the error estimations shown in Figs. 7 and 4 . Figure 7 was produced by the underestimated CO first guess, whereas Fig. 4 was produced by the true atmosphere as the first guess, except for the perturbed parameter. The relatively large error within the boundary layer (e.g., below $\sim 800 \mathrm{mb}$ ) is caused by poor CO-retrieval sensitivity as shown by $\mathrm{CO}$ weighting functions and the averaging kernel analysis. The analyses shown here are

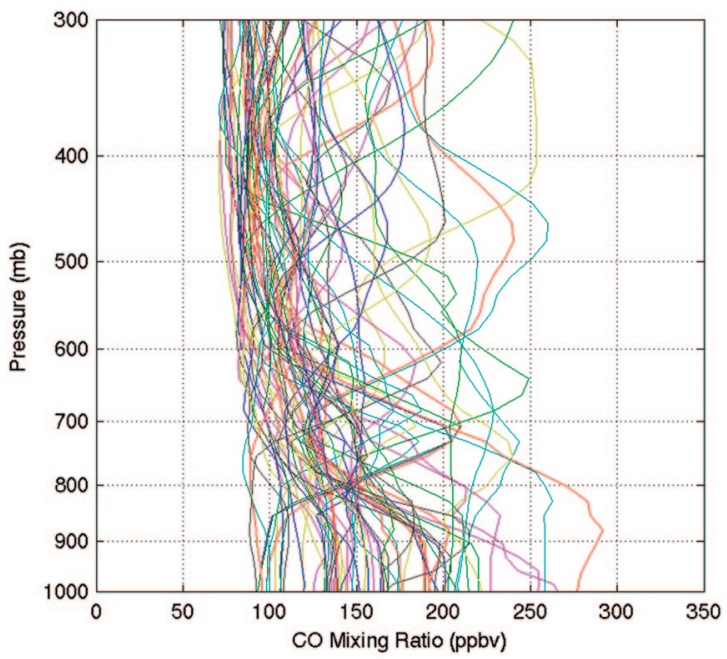

Fig. 11. In situ measured CO profiles used for retrieval analyses. 


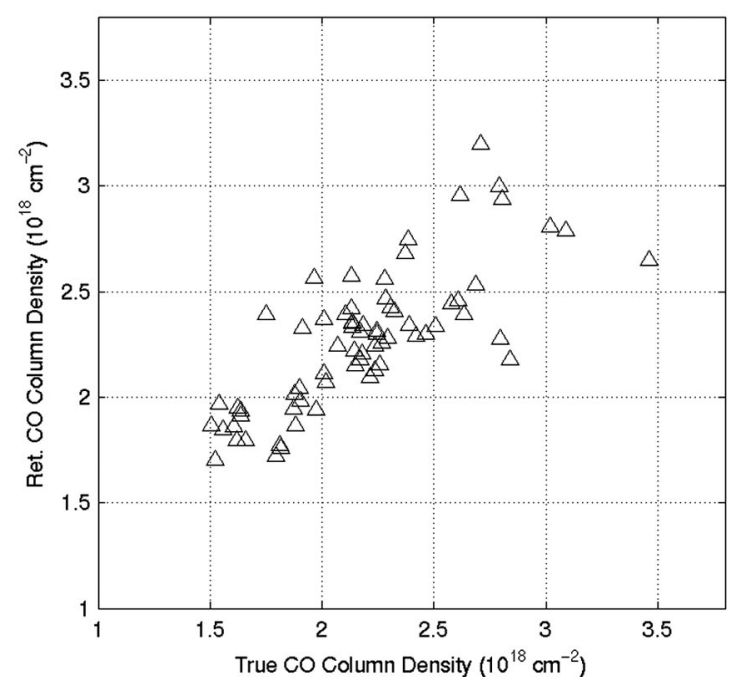

Fig. 12. Final CO PEI retrieved column density versus the truth (in situ measurement shown in Fig. 11) over 69 independent samples (see text).

simulated over water. However, the CO retrievalsensitivity in the boundary layer may depend on surface air and skin temperature contrast. The CO boundary-layer-retrieval sensitivity may increase when surface air and skin contrast is a maximum over land during the midafternoon.

\section{E. Analyses with In Situ Measured CO}

The retrieval analyses simulated in Subsections 3.C and 3.D are not absolutely independent because those CO profiles were generated in the same fashion in which $\mathrm{CO}$ profiles were produced for the training data set. Here, a set of Transport and Chemical Evolution over the Pacific; March, 2001 (TRACE-P) merged in situ measurements (up to a pressure altitude of $300 \mathrm{mb}$ ) of temperature, water vapor, $\mathrm{O}_{3}$, and $\mathrm{CO}$, a total of 69 profiles with a large $\mathrm{CO}$ distribution

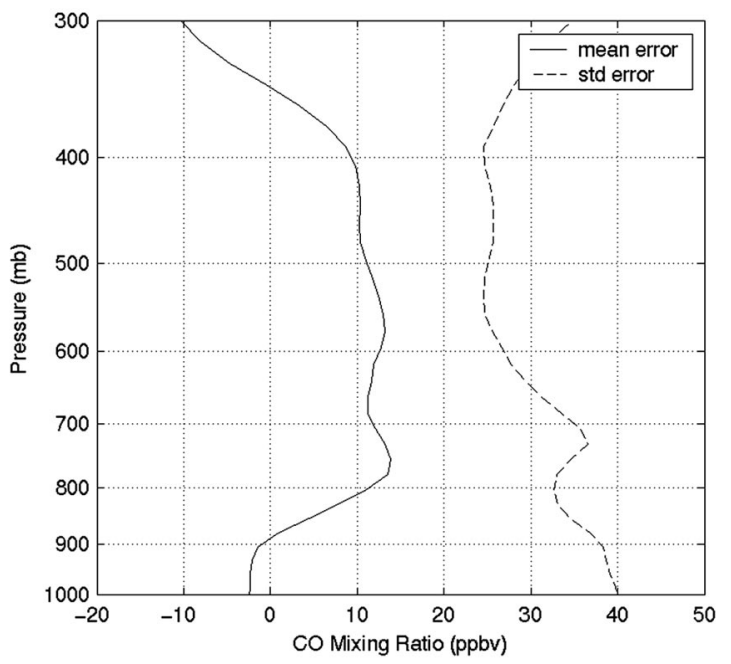

Fig. 13. Mean deviation and STDE of the final CO PEI retrieved profiles from their truth (in situ measurement shown in Fig. 11) over 69 independent samples (see text).
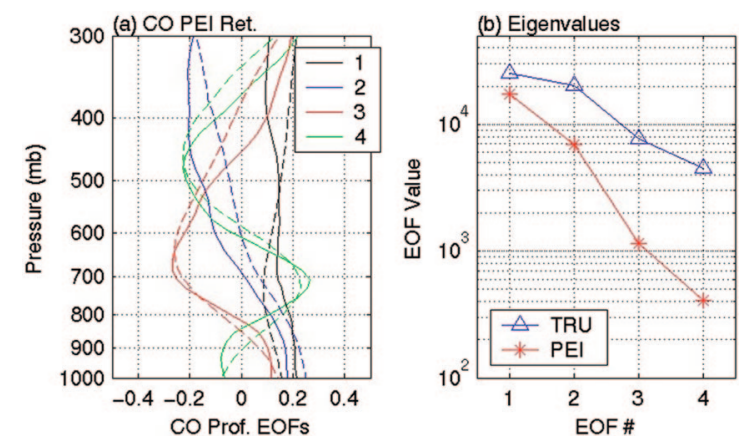

Fig. 14. (a) First four EOFs derived from the data sets of final CO PEI retrievals (the dashed curves in black, blue, red, and green are for EOF's 1, 2, 3, and 4, respectively) and are compared with those derived from the in situ CO profiles (solid curves). (b) Corresponding EOF values derived from the in situ measurements and retrievals.

diversity (i.e., relatively clean, polluted, and transported CO distributions shown in Fig. 11), was chosen here for retrieval testing as described above. These profiles are independent of the test set profiles used in development of the retrieval algorithm. Retrievals are performed on NAST-I radiance (with instrument noise) simulated from merged in situ measurements. The final retrieval results are compared with the truth (in situ measured), indicating that the total CO column density is captured (shown in Fig. 12; absolute mean difference, 8.44 $\times 10^{16} \mathrm{~cm}^{-2}$; STDE, $\left.2.59 \times 10^{17} \mathrm{~cm}^{-2}\right)$; and retrieved CO profile error (shown in Fig. 13) is expected from earlier subindependent retrieval simulations.

As shown above, one can assess the $\mathrm{CO}$ vertical resolution by averaging kernel performance. However, with a set of retrieved $\mathrm{CO}$ profiles the $\mathrm{CO}$ vertical resolution (or the vertical information content)
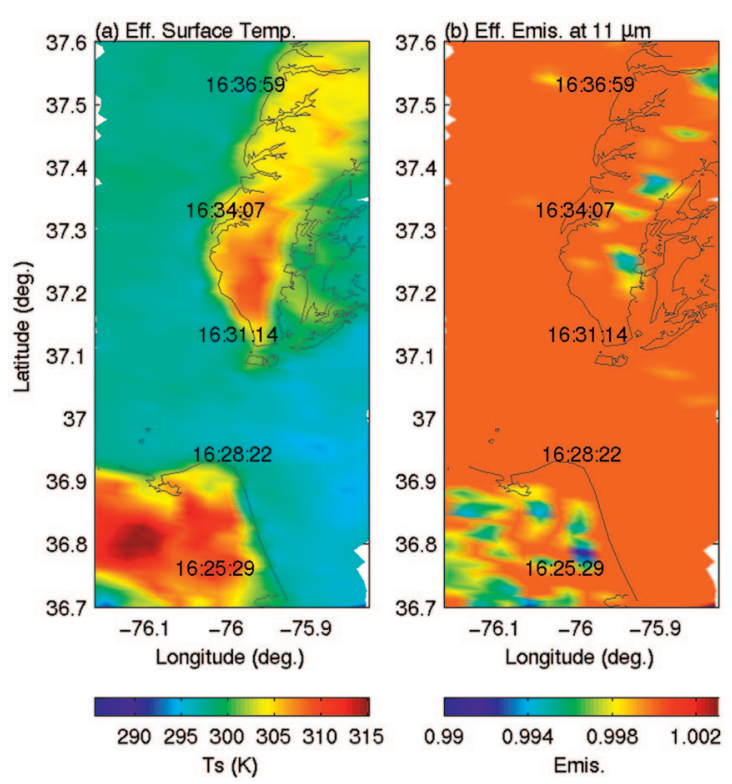

Fig. 15. Retrieved surface properties from a section of a NAST-I flight of 14 July 2001. The UT associated with the geophysical location is indicated in the figure. Eff., effective; Emis., emissions. 

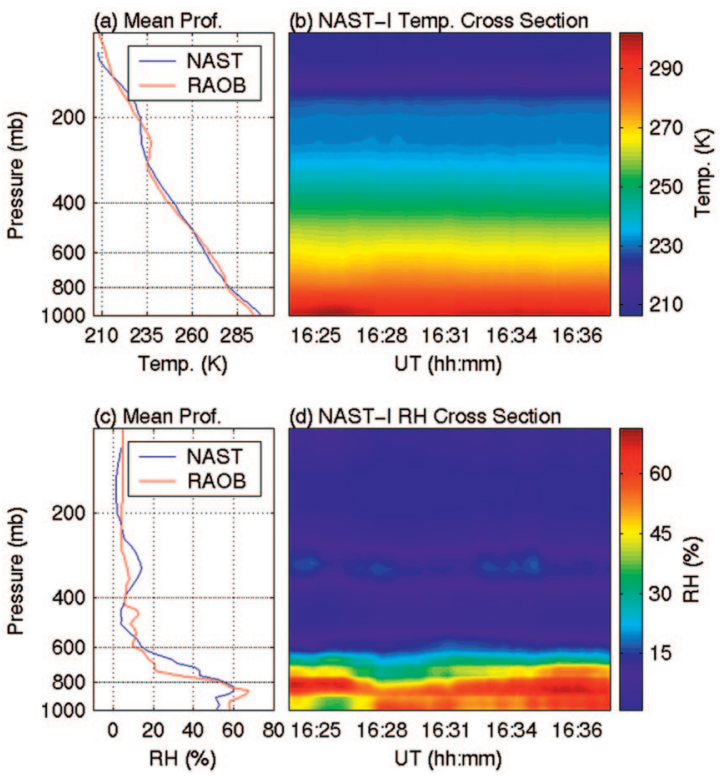

Fig. 16. Physically retrieved (SMI) temperature and relative humidity profiling (nadir mode) cross sections of the NAST-I observations associated with Fig. 15. The mean profile (Mean Prof.) is compared with a nearby radiosonde (RAOB); $\mathrm{RH}$, relative humidity.

can also be assessed by use of principal component analysis. This analysis allows us to estimate the vertical information content or vertical structure (eigenvectors) present in $\mathrm{CO}$ profiles and associated intensity (eigenvalues). Covariance matrices are calculated from these 69 in situ $\mathrm{CO}$ profiles and their corresponding retrieved profiles. Then the corresponding eigenvalues and eigenvectors that result from these covariance matrices are calculated. As shown in Fig. 14, the first four eigenvectors as well as the associated eigenvalues are in fair agreement between the truth and the final CO PEI retrieval, indicating that basic $\mathrm{CO}$ vertical distributions (i.e., few eigenvalues and associated eigenvectors) are nearly captured by the NAST-I retrievals.

The convergence through the physical iteration indicates that tropospheric $\mathrm{CO}$ can be retrieved from NAST-I measurements but with fairly poor accuracy in the profile as indicated from the weighting functions, averaging kernels, and statistical analysis (i.e., principal component analysis) of retrievals. However, NAST-I retrieved CO profiles are accurate for the column density computation. The close agreement between the observed and the retrieval-calculated radiances and the total $\mathrm{CO}$ column density derived from the retrieval indicate that, at the least, the total column amounts of $\mathrm{CO}$ are accurately retrieved from NAST-I data; this certainty is even further enhanced when NAST-I local observations are averaged to reduce the noise.

\section{NAST-I CO Retrievals}

A. CLAMS Retrieval of 14 July 2001

Retrievals obtained from real NAST-I measurements are presented in this section; these retrievals are
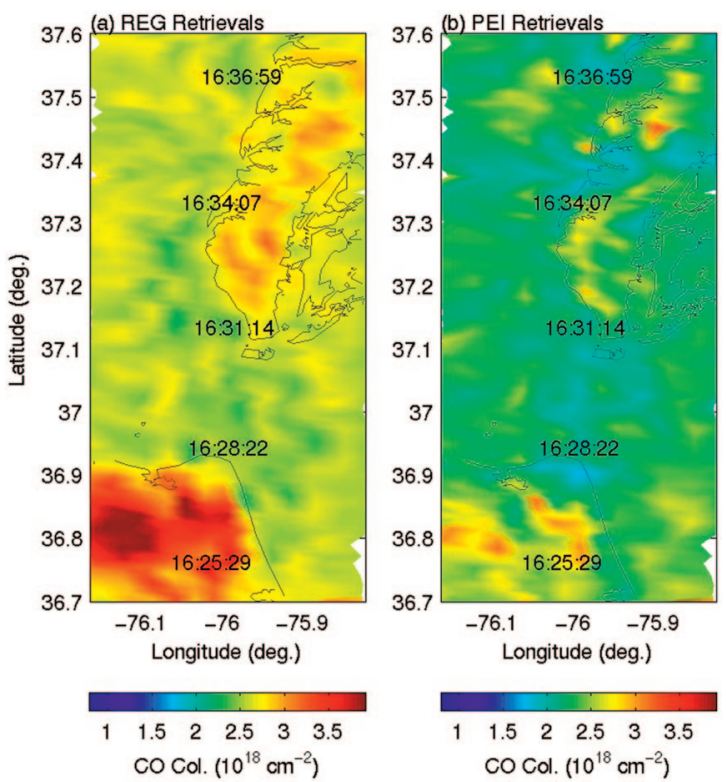

Fig. 17. NAST-I CO column (Col.) densities associated with Fig. 15 for (a) REG retrievals as first guesses (with a mean of 2.7 $\times 10^{18} \mathrm{~cm}^{-2}$ ) and for (b) final CO PEI retrievals (with a mean of $\left.2.3 \times 10^{18} \mathrm{~cm}^{-2}\right)$.

achieved without resorting to radiosonde tuning (i.e., radiance bias correction). Detailed validation of the retrieval methodology (REG and SMI) was performed to show accurate retrievals of thermodynamic parameters, such as temperature and water-vapor profiles. ${ }^{15}$ The temperature and water-vapor profiles can be validated by nearby radiosonde observations. A small sample of NAST-I data, collected from the Chesapeake Lighthouse and Aircraft Measurements for Satellite (CLAMS) field campaign of July 2001, is utilized to retrieve atmospheric and surface parameters in the three-stage retrieval process described above. Accordingly, the retrievals are presented as initial REG and final CO PEI products. Figures 15 and 16 show the final retrievals of the surface properties, temperature, and moisture profiles. The universal time (UT) is associated with the location shown in Fig. 15. The retrieved surface properties of skin temperature and emissivity correspond well to surface types such as land and water. Relatively warmer skin temperatures are shown over land than over water, as expected for daytime measurement conditions. The smaller emissivities (at $11 \mu \mathrm{m}$ ) associated with streets and building materials within the city of Norfolk, Virginia [lower left, Figs. 15(a) and 15(b)], are clearly evident. Figures 16(a) and 16(c) show the mean profiles over the vertical cross sections of temperature and relative humidity in comparison with a nearby radiosonde.

CO profiles from REG through PEI and their column density (from $200 \mathrm{mb}$ to the ground) are shown in both profiles. The $\mathrm{CO}$ column densities from the REG (used as the first guess) and final CO PEI retrievals are shown in Figs. 17(a) and 17(b), respectively. The average $\mathrm{CO}$ column densities over this 

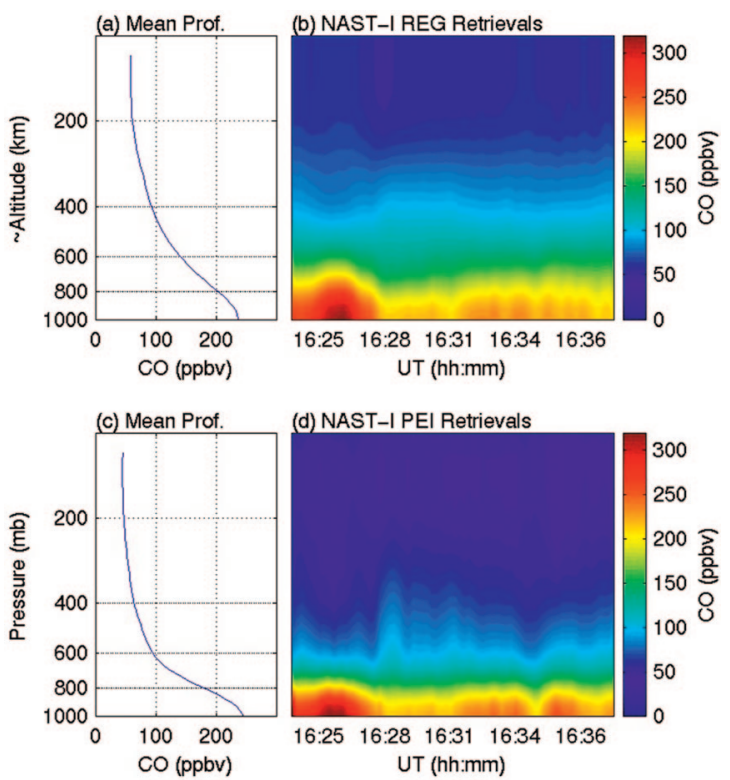

Fig. 18. REG and final CO PEI-retrieved CO cross sections (nadir mode) and their mean of the NAST-I observations associated with Fig. 15. Prof., profile.

area (a total of 910 measurements) are 2.7 $\times 10^{18} \mathrm{~cm}^{-2}$ (with a STDE of $0.30 \times 10^{18} \mathrm{~cm}^{-2}$ ) and $2.3 \times 10^{18} \mathrm{~cm}^{-2}$ (with a STDE of $0.25 \times 10^{18} \mathrm{~cm}^{-2}$ ) as obtained from REG and the final CO PEI, respectively. Unfortunately, this set of CO retrievals cannot be fully validated because of the lack of coordinated and coincident in situ verification measurements (i.e., ground truth). One has to rely on qualitative validation by use of appropriate climatologic data. The mean-REG retrieved CO column of $2.7 \times 10^{18} \mathrm{~cm}^{-2}$ reflects an environment such as large pollution or fire, ${ }^{10,30,31}$ whereas the final PEI-retrieved $\mathrm{CO}$ column of $2.3 \times 10^{18} \mathrm{~cm}^{-2}$ still indicates a somewhat lesser industrially polluted environment. As indicated by the simulation analyses, a relatively larger error can be introduced when other atmospheric and surface parameters are simultaneously retrieved with their uncertainties. However, one can greatly reduce the retrieval error (i.e., random error) by coadding the retrievals. The REG and final CO PEI cross sections from the nadir mode along the aircraft track are shown in Figs. 18(a) and 18(b), respectively. Furthermore, the radiance comparison described in the retrieval simulation is used to validate the radiance convergence from initial REG to final PEI retrieval. The retrievals are used to compute the NAST-I spectral radiances in comparison with their associated NAST-I observed radiances. The radiance STDE and the mean radiance difference are shown in Figs. 19 and 20, respectively. The improvement (i.e., convergence) made by the subsequent physical iteration retrieval is evident. In particular, the radiance residual in the $\mathrm{CO}$ band region is significantly reduced from the REG to physical nonlinear PEI. The residuals that remain after the physical retrieval indicate that the retrieval accuracy for all the param-
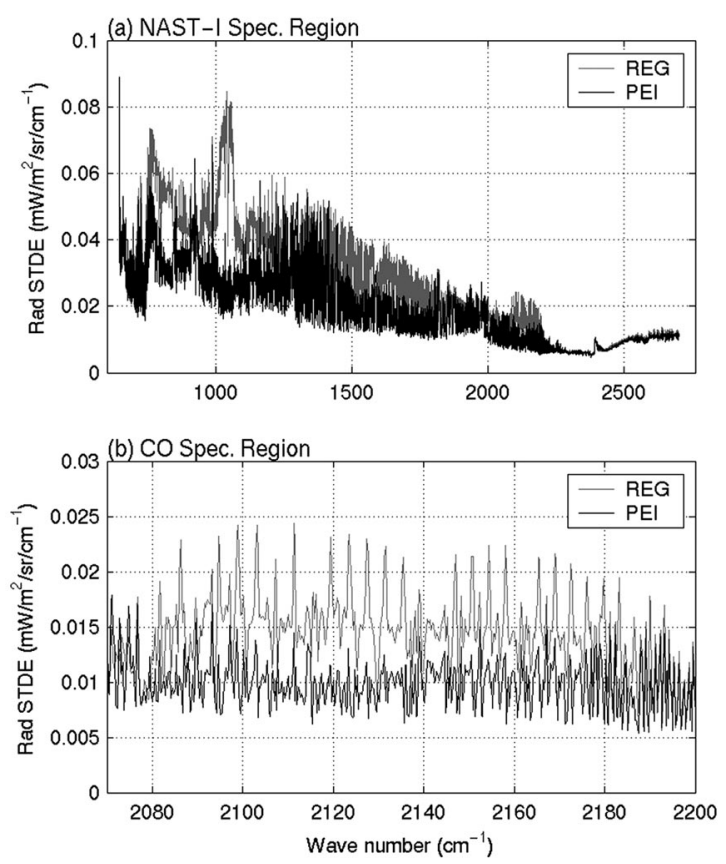

Fig. 19. Statistical analyses of STDE between observed and retrieval-calculated radiances ( $\mathrm{Rad})$ over the retrieved samples (a total of 910 samples shown in Fig. 15).

eters is limited by instrument noise. The agreement between the observation and retrieval-calculated radiance indicates that, at the least, the total column amounts of CO are accurately achieved. Although $\mathrm{O}_{3}$ retrieval is not within the scope of this paper, it is worthwhile to point out that the radiance convergence in the $\mathrm{O}_{3} 9.6-\mu \mathrm{m}$ band region reveals that an accurate $\mathrm{O}_{3}$ column amount is obtained through the physical nonlinear iterative retrieval. As the $\mathrm{O}_{3}(101-000)$ band region (approximately 1968$2164 \mathrm{~cm}^{-1}$ ) appears within the CO $4.7-\mu \mathrm{m}$ band region, the simultaneous retrieval of the total $\mathrm{O}_{3}$ amount benefits the accuracy of $\mathrm{CO}$ profile retrieval.

\section{B. TRACE-P Retrieval of 13 March 2001}

Another field campaign, TRACE-P, provided CO in situ measurements ${ }^{32}$ from a NASA DC-8 aircraft while NAST-I, aboard Proteus, flew nearby over the western Pacific Ocean. The duration of the DC-8 flight was from 2:15 to 10:25 UT (13 March 2001), whereas Proteus was airborne from 0:12 to 5:12 UT on 12 March 2001. As shown in Fig. 21(a), the DC-8 was near $22 \mathrm{~N}$ latitude, ascending and descending to a vertical profile (with the aircraft) five times. Proteus took off from Okinawa, Japan, ascended to a cruising altitude of $\sim 14 \mathrm{~km}$, and then flew northwest. Although these two aircraft were not at exactly the same location at the same time (they were approximately 1 day apart), these flights still provided a unique opportunity to compare NAST-I CO retrievals roughly with nearby in situ CO profile measurements. NAST-I retrievals from the most southern portion (approximately $29 \mathrm{~N}-30 \mathrm{~N}$ latitude, $\sim 10 \mathrm{~min}$ in duration) of the Proteus flight, after the aircraft 
(a) NAST-I Spec. Region
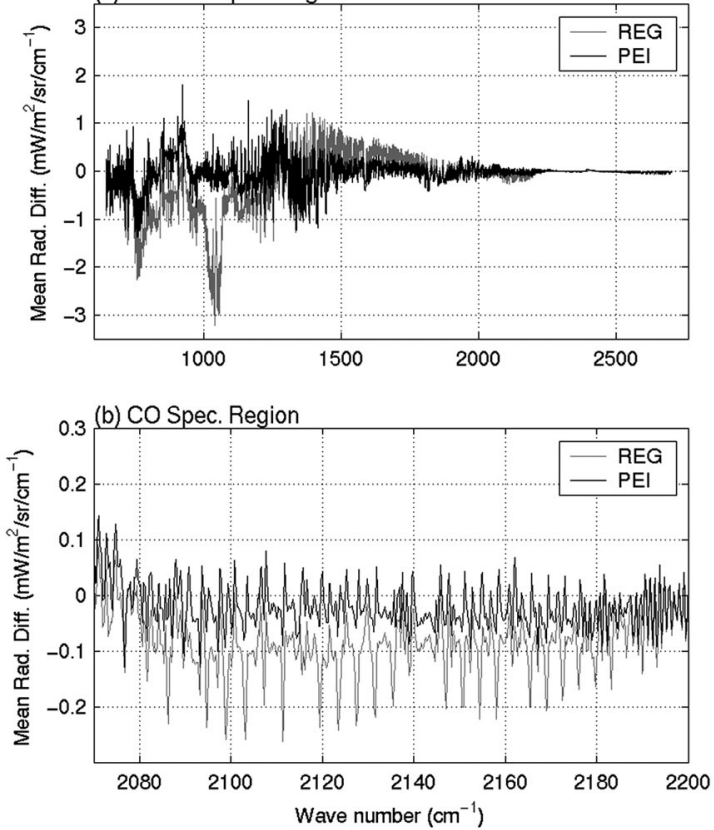

Fig. 20. Statistical analyses of the mean radiance difference between observed and retrieval-calculated radiances over the retrieved samples (a total of 910 samples shown in Fig. 15).

reached a stable altitude, are used for comparison with the in situ measurements. The vertical cross section of NAST-I CO retrievals (from the final retrieval stage) is plotted in Fig. 21(c), and its mean profile is plotted in Fig. 21(b), showing good agreement between final NAST-I retrieval and in situ CO profiles. The $\mathrm{CO}$ variation was indicated by both in situ measurements and NAST-I retrievals; discrepancies that depend on specific location and time differences between the remote NAST-I and the in situ $\mathrm{CO}$ measurements may exist.

\section{U.S. East Coast CO Measurements}

Numerous field campaigns were conducted over the U.S. East Coast. Figure 22 shows the NAST-I retrieved CO column density mapped from seven flights along the U.S. East Coast (from approximately $24 \mathrm{~N}$ to $42 \mathrm{~N}$ latitude) during the summer season (mostly

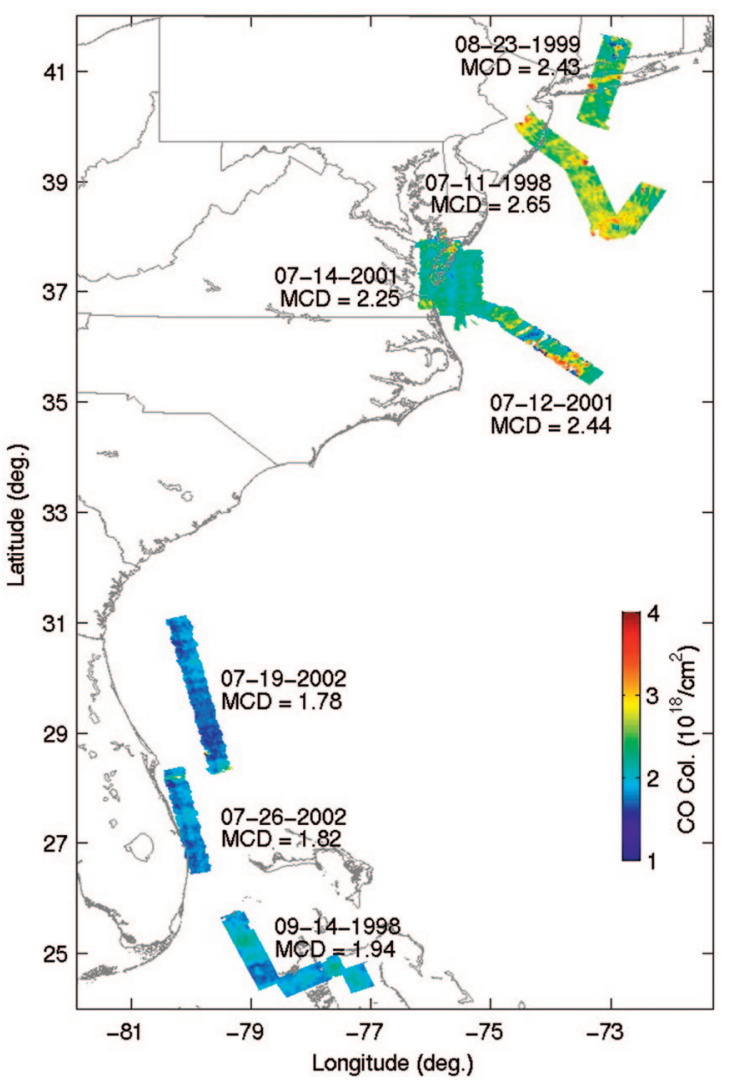

Fig. 22. NAST-I retrieved CO column density map from seven NAST-I flights along the U.S. East Coast. The mean column density $\left(\mathrm{MCD}, \times 10^{18} / \mathrm{cm}^{2}\right)$ for each flight is plotted in the figure.

July) collected from 1998 to 2002 . In spite of the time difference and possible different industrial influences from inland, the $\mathrm{CO}$ distribution shows latitudinal dependence. The $\mathrm{CO}$ abundance is more pronounced in the higher-latitude region; the mean $\mathrm{CO}$ column density of each flight is plotted in Fig. 22. The mean profiles from each flight are shown in Fig. 23; the different vertical distributions from these profiles indicate widely different $\mathrm{CO}$ distributions among these flights. The random error in the averaged retrieval (more than thousands of measurements) is greatly reduced. Despite the systematic error, the relative
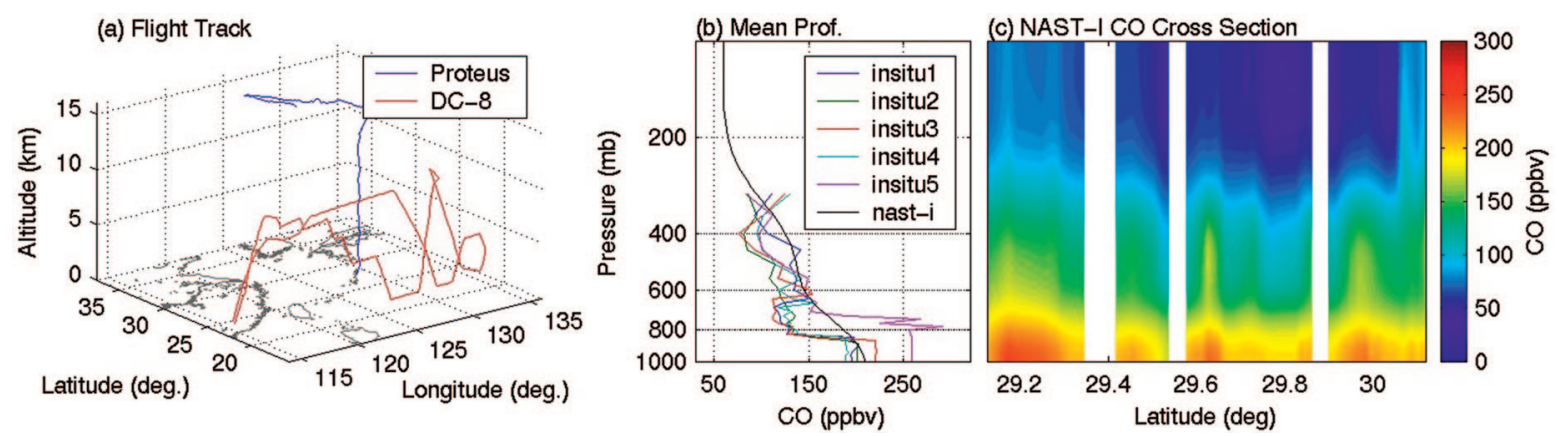

Fig. 21. (a) Flight tracks of the DC-8 flight (13 March 2001) and the Proteus flight over the Pacific Ocean (12 March 2001), (b) NAST-I mean profile of CO physical enhancement retrievals compared with DC-8 in situ measurements, and (c) a vertical cross-section segment of NAST-I CO retrievals closest to DC-8 in situ CO measurements. 


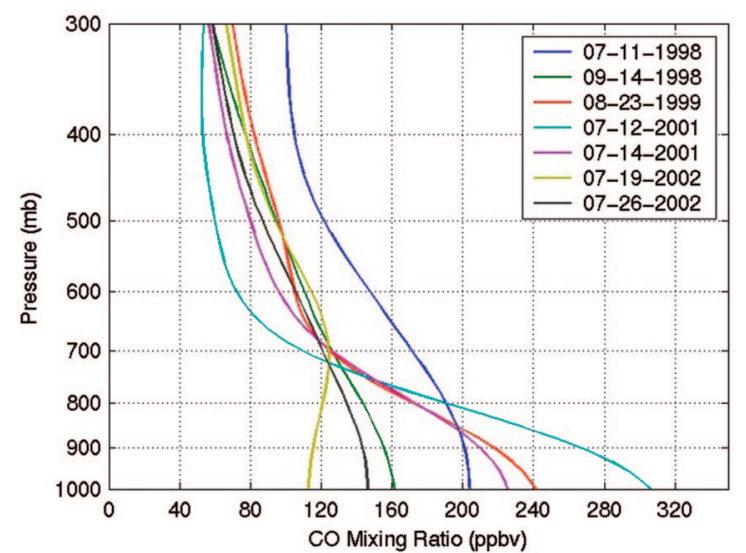

Fig. 23. NAST-I average CO profile from each flight associated with Fig. 22.

quantity (e.g., the deviation from the mean) shows the $\mathrm{CO}$ distribution from flight to flight monitored with NAST-I infrared measurements. It is worthwhile to point out that the large variation in the altitude region below $800 \mathrm{mb}$ is produced mainly by the first guess that results from the REG, and the overall profile accuracy was discussed and indicated in earlier analyses. Although these retrievals are not validated because of the lack of truth data, the mean tropospheric CO profile at $0-14 \mathrm{~km}$ is comparable to the previous in situ measurements. ${ }^{30,33,34}$ As illustrated in Fig. 24, NAST-I tropospheric averaged CO abundances show a latitudinal distribution that varies from $\sim 80$ to $\sim 150$ parts in $10^{9}$ by volume in the latitude region of approximately $24 \mathrm{~N}-42 \mathrm{~N}$, which is similar to results of previous in situ measurements. Such previous measurements were obtained at $8-11 \mathrm{~km}$ (October-March), ${ }^{33}$ at $5.0-6.5 \mathrm{~km}$ (May), ${ }^{34}$ and at $0-14 \mathrm{~km}$ (July-August). ${ }^{30}$ Despite the altitude intervals and seasonal differences among these data,

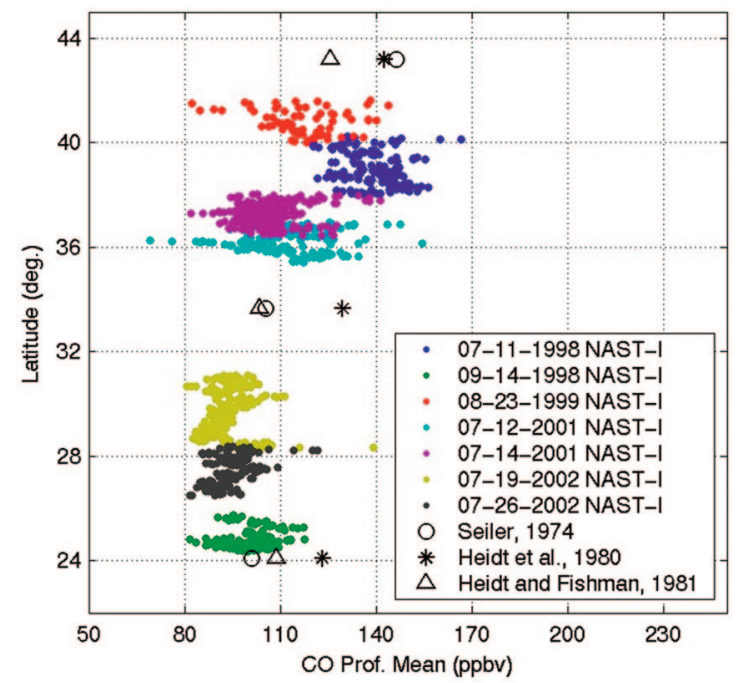

Fig. 24. Latitudinal distribution of tropospheric mean CO from NAST-I retrievals (along the U.S. East Coast) shown in Fig. 22 and the distributions obtained in earlier studies (see text). the agreement in the $\mathrm{CO}$ latitudinal distribution trend is evident. The consistent thermodynamic parameters and $\mathrm{CO}$ column density retrievals from numerous NAST-I flights indicate not only a stabilized retrieval algorithm but also consistently accurate NAST-I spectral radiance observations over the years.

\section{Conclusions}

An inversion algorithm for tropospheric CO profile retrieval from Fourier-transform spectroscopy nadir observations has been developed, tested, and demonstrated with NAST-I measurements. In particular, the $\mathrm{CO}$ profile retrieval approach was developed and analyzed by use of forward and inverted simulations together with NAST-I measurements for retrieval tests. The results validate the integrity of the retrieval approach. NAST-I CO retrieval samples demonstrate the ability of the retrieval algorithm to capture not only temperature and moisture profile variations but $\mathrm{CO}$ variations as well. Furthermore, the vertical profile comparison with nearby in situ measurements of 12-13 March 2001 shows reasonable agreement; the latitudinal distribution along the U.S. East Coast shows comparable agreement with previous in situ measurements. Additional profile validation analyses to provide more-definitive conclusions have been strongly desired. These validation measurements were obtained during both July and September 2004, while the NAST operated aboard the Proteus aircraft for the Intercontinental Chemical Transport Experiment and the European AQUA Thermodynamic Experiment missions during which in situ data were gathered by the NASA DC-8 and the UK Met Office BAe146 aircraft, respectively. In any case, the retrieval analyses and preliminary NAST-I results presented here demonstrate that tropospheric $\mathrm{CO}$ abundance can be retrieved from accurate nadir observations of spectrally resolved radiances as achieved with a Fourier-transform spectrometer.

The NAST-I program is supported by the NPOESS Integrated Program Office. The NAST-I OSS model was developed at Atmospheric and Environmental Research, Inc. The authors express sincere thanks to the NAST-I team members from various organizations. The authors acknowledge support from NASA Langley Research Center.

\section{References}

1. H. Levy II, "Natural atmosphere: large radical and formaldehyde concentrations predicted," Science 173, 141-143 (1971).

2. J. Fishman, K. Fakharuzzaman, B. Cros, and D. Nganga, "Identification of widespread pollution in the Southern Hemisphere deduced from satellite analyses," Science 252, 16931696 (1990).

3. P. J. Crutzen, L. E. Heidt, J. P. Krasnec, and W. H. Hollock, "Biomass burning as a source of atmospheric gases $\mathrm{CO}, \mathrm{H}_{2}$, $\mathrm{N}_{2} \mathrm{O}, \mathrm{NO}, \mathrm{CH}_{3} \mathrm{Cl}$, and COS," Nature 282, 253-256 (1979).

4. J. R. Drummond, "Measurements of Pollution in the Troposphere (MOPITT)," in The Use of EOS for Studies of Atmospheric Physics, J. C. Gille and G. Visconti, eds. (NorthHolland, Amsterdam, 1992), pp. 1269-1284. 
5. L. Pan, J. C. Gille, D. P. Edwards, P. L. Bailey, and C. D. Rodgers, "Retrieval of tropospheric carbon monoxide for the MOPITT experiment,” J. Geophys. Res. 103, 32,277-32,290 (1998).

6. M. N. Deeter, L. K. Emmons, G. L. Francis, D. P. Edwards, J. C. Gille, J. X. Warner, B. Khattatov, D. Ziskin, J.-F. Lamarque, S.-P. Ho, V. Yudin, J.-L. Attié, D. Packman, J. Chen, D. Mao, and J. R. Drummond, "Operational carbon monoxide retrieval algorithm and selected results for the MOPITT instrument," J. Geophys. Res. 108(D14), 4399, 10.1029/ 2002JD003186 (2003).

7. R. Beer, T. A. Glavich, and D. M. Rider, "Tropospheric emission spectrometer for the Earth Observing System's Aura satellite," Appl. Opt. 40, 2356-2367 (2001).

8. D. Q. Wark and H. E. Fleming, "Indirect measurements of atmospheric temperature profiles from satellite. I. Introduction," Mon. Weather Rev. 94, 351-362 (1966).

9. W. L. Smith and H. M. Woolf, "The use of eigenvectors of statistical co-variance matrices for interpreting satellite sounding radiometer observations," J. Atmos. Sci. 33, 11271140 (1976).

10. W. W. McMillan, L. L. Strow, W. L. Smith, H. E. Revercomb, H. L. Huang, A. M. Thompson, D. P. McNamara, and W. F. Ryan, "Remote sensing of carbon monoxide over the continental United States on September 12-23, 1993," J. Geophys. Res. 102, 10,695-10,709 (1997).

11. C. Clerbaux, J. Hadji-Lazaro, S. Turquety, G. Mégie, and P.-F. Coheur, "Trace gas measurements from infrared satellite for chemistry and climate application," Atmos. Chem. Phys. 3, 1495-1508 (2003).

12. D. Cousins and W. L. Smith, "National Polar-Orbiting Operational Environmental Satellite System (NPOESS) Airborne Sounder Testbed-Interferometer (NAST-I)," in Application of Lidar to Current Atmospheric Topics II, A. J. Sedlacek and K. W. Fischer, eds., Proc. SPIE 3127, 323-331 (1997).

13. W. L. Smith, A. M. Larar, D. K. Zhou, C. A. Sisko, J. Li, B. Huang, H. B. Howell, H. E. Revercomb, D. Cousins, M. J. Gazarik, and D. Mooney, "NAST-I: results from revolutionary aircraft sounding spectrometer," in Optical Spectroscopic Techniques and Instrumentation for Atmospheric and Space Research III, A. M. Larar, ed., Proc. SPIE 3756, 2-8 (1999).

14. W. L. Smith, D. K. Zhou, F. W. Harrison, H. E. Revercomb, A. M. Larar, H. L. Huang, and B. Huang, "Hyperspectral remote sensing of atmospheric profiles from satellites and aircraft," in Hyperspectral Remote Sensing of the Land and Atmosphere, W. L. Smith and Y. Yasuoka, eds., Proc. SPIE 4151, 94-102 (2001).

15. D. K. Zhou, W. L. Smith, J. Li, H. B. Howell, G. W. Cantwell, A. M. Larar, R. O. Knuteson, D. C. Tobin, H. E. Revercomb, and S. A. Mango, "Thermodynamic product retrieval methodology for NAST-I and validation," Appl. Opt. 41, 6957-6967 (2002).

16. C. Clerbaux, J. Hadji-Lazaro, P. Sebastien, C. Camy-Peyret, J. Wang, D. P. Edwards, and M. Luo, "Retrieval of CO from nadir remote-sensing measurements in the infrared by use of four different inversion algorithms," Appl. Opt. 41, 7068-7078 (2002).

17. X. Liu, J.-L. Moncet, D. K. Zhou, and W. L. Smith, "A fast and accurate forward model for NAST-I instrument," in Fourier Transform Spectroscopy and Optical Remote Sensing of Atmo- sphere, 2003 Technical Digest Series OSA (Optical Society of America, Washington, D.C., 2003), p. 16.

18. W. J. Wiscombe and J. W. Evans, "Exponential-sum fitting of radiative transmission functions," J. Comput. Phys. 24, 416444 (1977).

19. J. L. Moncet, X. Liu, H. Rieu-Isaacs, H. Snell, S. Zaccheo, R. Lynch, J. Eluszkiewicz, Y. He, G. Uymin, C. Lietzke, J. Hegarty, S. Boukabara, A. Lipton, and J. Pickle, "Algorithm theoretical basis document (ATBD) for the Cross Track Infrared Sounder (CrIS) environmental data records (EDR)," V1.2.3, AER document P882-TR-E-1.2.3-ATBD-03-01 (Atmospheric and Environmental Research, Boston, Mass., 2003).

20. S. A. Clough, M. J. Iacono, and J. L. Moncet, "Line-by-line calculations of atmospheric fluxes and cooling rates: Application to water vapor," J. Geophys. Res. 97, 15,761-15,785 (1992).

21. X. Liu, Science Directorate, NASA Langley Research Center, 21 Langley Boulevard, Hampton, Va. 23681 (personal communication, 2004).

22. J. Li, "Temperature and water vapor weighting functions from radiative transfer equation with surface emissivity and solar reflectivity," Adv. Atmos. Sci. 11, 421-426 (1994).

23. X. L. Ma, T. J. Schmit, and W. L. Smith, "A nonlinear physical retrieval algorithm-its application to the GOES-8/9 sounder,” J. Appl. Meteorol. 38, 501-513 (1999).

24. S. Twomey, "On the numerical solution of Fredholm integral equations of the first kind by inversion of the linear system produced by quadrature," J. Assoc. Comput. Mach. 10, 97-101 (1963).

25. A. N. Tikhonov, "On the solution of incorrectly stated problems and a method of regularization," Dokl. Acad. Nauk. SSSR 151, 501-504 (1963).

26. C. D. Rodgers, "Retrieval of atmospheric temperature and composition from remote measurements of thermal radiation," Rev. Geophys. Space Phys. 14, 609-624 (1976).

27. P. C. Hansen, Rank-Deficient and Discrete Ill-Posed Problems. Numerical Aspects of Linear Inversion (SIAM, Philadelphia, Pa., 1998).

28. C. D. Rodgers, "Characterization and error analysis of profile retrieved from remote sounding measurements," J. Geophys. Res. 95, 5587-5595 (1990).

29. C. D. Rodgers, Inversion Methods for Atmospheric Sounding: Theory and Practice (World Scientific, River Edge, N.J., 2000).

30. W. Seiler and J. Fishman, "The distribution of carbon monoxide and ozone in the free troposphere," J. Geophys. Res. 86, 7225-7265 (1981)

31. G. P. Anderson, S. A. Clough, F. X. Kneizys, J. H. Chetwynd, and E. P. Shettle, "AFGL atmospheric concentration profiles (0-120 km)," Tech. Rep. AFGL-TR-86-0110 (U.S. Air Force Geophysics Laboratory, Hanscom Air Force Base, Mass., 1987).

32. G. W. Sachse, G. F. Hill, L. O. Wade, and M. G. Perry, "Fastresponse, high-precision carbon monoxide sensor using a tunable diode laser absorption technique," J. Geophys. Res. 92, 2071-2081 (1987).

33. W. Seiler, "The cycle of atmospheric CO," Tellus 26, 117-135 (1974).

34. L. E. Heidt, J. P. Krasnec, R. A. Lueb, W. H. Pollock, B. E. Henry, and P. J. Crutzen, "Latitudinal distribution of CO and $\mathrm{CH}_{4}$ over the Pacific,” J. Geophys. Res. 85, 7329-7336 (1980). 